Please cite as:

Higgins A, Tuohy T, Murphy R, Begley C. Mothers with mental health problems:

contrasting experiences of support within maternity services in the Republic of Ireland.

Midwifery 2016 May;36:28-34

Mothers with mental health problems: contrasting experiences of support within maternity services in the Republic of Ireland 


\begin{abstract}
Objective: to explore the views and experiences of women with mental health difficulties, in the Republic of Ireland, accessing and receiving care from publicly-funded maternity care services during pregnancy, childbirth and immediate postnatal period in hospital.

Participants: In total 20 women with a range of mental health problems were recruited. The women had given birth within maternity services with and without specialist perinatal mental health services.

Design: A qualitative descriptive design using in-depth face to face interviews was used to explore women's experience. Data were analysed using an inductive thematic process. Findings: the study offers valuable insights into the maternity care experiences of women with mental health problems, and highlights the deficits and fragmentation of care in maternity units that do not have a specialist mental health service. Even when the women voluntarily disclosed their difficulties, midwives appeared to lack the knowledge and skills to respond sensitively and responsively.

Key conclusions and implications for practice: there is a need to expand perinatal mental health services in the Republic of Ireland, so that quality service provision is not dependent on geography. In addition, there is a need for education to address the lack of knowledge and understanding of perinatal mental health problems amongst maternity care practitioners.
\end{abstract}

Key words: perinatal mental health, qualitative research, women's experiences, maternity services. 


\section{Mothers with mental health problems: contrasting experiences of support within maternity services in Ireland}

\section{INTRODUCTION}

For most women, pregnancy and motherhood is a positive psychological process. However, for some women this life-changing event can result in the development of a new mental health problem or the re-emergence of an existing problem. It is estimated that $15-25 \%$ of women will develop a mental health problem either during pregnancy or the first year post pregnancy (NICE, 2014). Fifteen per cent of women will experience depression during pregnancy and between $15 \%-20 \%$ of women will experience some form of depression in the first 12 months postnatally. Post-traumatic stress disorder is estimated to occur in $3 \%$ of women, and 6\% following emergency caesarean section (Ross \& McLean, 2006). The rate of anxiety disorder is estimated to be between $14-15 \%$, with a recognition that anxiety disorder is often comorbid with depressive disorders, and one to two women per 1,000 births experience the onset of psychosis, often termed postpartum or puerperal psychosis (Higgins et al., 2012, NICE, 2014).

A number of studies have also highlighted the potential for reoccurrence and/or the worsening of existing mental health problems. In particular, the reported reoccurrence rates for bipolar disorder are approaching 50\% in the antenatal period and $70 \%$ in the postnatal period (Viguera et al., 2007). Women with a diagnosis of schizophrenia are at an increased risk of psychosis (Munk-Olsen et al., 2006, Munk-Olsen et al., 2009), whilst women with a history of depression are also at an increased risk of its recurrence, continuation, or exacerbation (Bennet, 2004). Pregnancy can also worsen symptoms for women with preexisting binge eating disorder (Watson et al., 2013); hence the importance of mental health support throughout pregnancy, birth and early motherhood.

Untreated maternal mental distress, either in pregnancy or postnatally, can have potential negative consequences on the mother, foetus and baby, including in the extreme case, maternal suicide (Oates and Cantwell, 2011). Maternal mental distress can be associated with increased rate of stillbirth, pre-term birth, post-natal specialist care for the baby, and low birth-weight babies (Ding et al., 2014, Kim et al., 2013). Untreated mental health 
problems in pregnancy are also associated with poorer long-term outcomes for children, including decreased emotional and cognitive development, and difficulties developing and maintaining relationships and attachment (Fendrich et al., 1990, Goodman and Brumley 1990, Hammen et al., 1990, Kelly et al., 1999, Mullick et al., 2001). While perinatal mental health issues are a major health concern, early detection, prompt intervention, and support can improve maternal and infant outcomes.

The focus of this paper is on the findings of a study into the experiences of women with mental health difficulties as they access and use Irish maternity care services. The study was part of a larger research programme exploring the strengths and weaknesses of publiclyfunded health services, in the Republic of Ireland, provided to five different cohorts of women with disabilities (women with visual impairment, hearing impairment, physical disability, mental health difficulty or intellectual disability) in relation to pregnancy, childbirth and early motherhood (up to 2 years) (Reference to be inserted post peer review). This article reports the findings pertaining only to data collected with women with mental health difficulties, and specifically focuses on their interaction with maternity care services during pregnancy, birth and the immediate postnatal period in hospital.

\section{METHODS}

Both phenomenology and grounded theory approaches were considered, but as the aim was not to develop a theory for testing, nor to conduct an in-depth exploration of women's experiences, a qualitative descriptive design was chosen. This design lends itself to initial exploration of a wide variety of participants' views in order to learn from them.

\section{Objective}

The objective of the study was to explore the views and experiences of women with mental health difficulties, in the Republic of Ireland, accessing and receiving care from publiclyfunded maternity services during pregnancy, childbirth and immediate postnatal period in hospital.

\section{Inclusion criteria}

To be included in the study women had to: 
- have experienced mental health challenges which required contact with the mental health services prior to becoming pregnant.

- have experienced a new mental health problem during pregnancy or in the postnatal period (up to two years postnatally).

- be currently pregnant, and/or have given birth in the previous two years.

- have experience of public maternity services in the Republic of Ireland

- be English speaking and aged 18 years or over.

\section{Participant Recruitment}

A multipronged approach to recruitment was undertaken. Recruitment strategies included posters advertising in maternity hospitals, and a national advertising campaign via specialist magazines, newsletters and websites of key representative bodies. Information about the study was also disseminated to mental health support groups, and psychiatric teams and medical social workers in the only two maternity hospitals that provided specialist mental health services within the Republic of Ireland. As the study progressed, some women were recruited through snowballing as the women passed on information leaflets to others.

\section{Consent and ethics}

An initial letter and information brochure was sent to all women who fulfilled the inclusion criteria, and contacted the team offering to take part. Those who indicated their willingness to be interviewed were contacted by a member of the research team, who answered any questions and arranged a suitable time and venue to meet and conduct the interview. Each participant was asked to sign a form prior to interview, consenting to be interviewed and the interview being digitally recorded, and a second form at the end of the interview consenting for data to be used in the study and publications. At all times the women's wellbeing took priority over the research. The name and contact details of people within the maternity and mental health services who were willing to give follow-up emotional support were given to women, if required, in addition to an information sheet of contact details for support groups, services, and web-site information. The team also had access to a registered clinical psychologist who acted as a mechanism of referral for any woman who 
might require such a service. Ethical approval to conduct the study was received from the university ethics committee and services involved.

\section{Study Sample}

A sample size of 18 women was initially planned, but recruitment and data collection continued until saturation was reached. In total twenty women recounted their experiences of accessing health services during pregnancy, childbirth and in postnatal period. A total of 22 interviews were conducted, as one woman was interviewed on 3 occasions, in pregnancy, in the first 6 months postpartum and in early motherhood. The age range was 23-40 years $($ mean $=33.05$ years, $S D=4.17)$. Sixteen women were married and four were cohabiting. Seven described their occupation as professional, three as skilled, two as semiskilled and eight as homemaker. Five women received fertility treatment. Six of the women had caesarean sections.

Ten of the women interviewed had a diagnosis of mental health difficulty prior to becoming pregnant, including a diagnosis of psychosis, obsessive compulsive disorder (OCD), bipolar disorder, post-traumatic stress disorder (PTSD), depression, depression with anxiety, anxiety, phobia and substance misuse. Of the ten women who developed mental health problems during pregnancy or in the postnatal period, six were given a diagnosis of postnatal depression, the remainder experienced depression during pregnancy, anxiety, or psychosis. Ten women discussed their experiences during their first pregnancy and ten recounted their experiences during their second or subsequent pregnancies. Six women were interviewed during pregnancy, sixteen were interviewed in the post-natal period.

\section{Data Collection}

Interviews were conducted by two of the authors (X1 and X2). A flexible interview guide, developed from a comprehensive literature review, and modified in response to individual and group-specific needs, was used (see table 1). Positively phrased open questions, paraphrases and prompts were used to elicit maximum information from the women and seek clarity. The duration and format of interviews was woman-led and interviews lasted from 30-90 minutes.

Insert table 1: Interview schedule 


\section{Data Analysis}

All interview data were audio-recorded and transcribed in full and any names that could identify the participant were removed. To ensure accuracy during the transcribing process the digitally recorded interview and written transcript were listened to, and read simultaneously, a number of times. The computer software package NVivo 8 was used to assist in the management of data. An inductive thematic approach informed the analytical process. Written transcripts were examined systematically, and coded line by line. Categories of analysis were developed, from which the main themes emerged. When a number of interviews were coded by one of the researchers, the transcripts were examined by other members of the research team. Themes emerging following this analysis were then compared to those that were generated by the first researcher, in the process of peer debriefing. The themes were generally consistent and consensus was reached.

\section{FINDINGS}

Four themes were identified: 1) Lack of integrated and women centred services; 2) Feeling misunderstood; 3) A veil of secrecy; and 4) A way forward: experiences of specialist Perinatal Mental Health Services.

\section{Lack of integrated and women centred services}

The vast majority of women reported extreme difficulties in accessing support for their mental health needs, with a sense that they were hostage to the fragmentation and lack of integration between maternity care and mental health services. In the maternity services, attention and focus was primarily on the medical health of mother and foetus with little, if any, acknowledgment of, or engagement with, women's emotional and/or mental health needs. Women were, as a result, confronted with the belief that the emotional and mental realms of their pregnancies fell outside the domains of motherhood and, thus, maternity service provision.

'They [maternity services] didn't offer me anything...as far as I was aware there wasn't anything to offer...I think they just kind of thought...."ah well if you're being seen by the psychiatric services then we don't need to do anything".' (7) 
'I fell between the stools, the maternity service washed their hands and said "well we're not dealing with it because it's a mental health issue," mental health were saying "we're not dealing with it, she's pregnant".' (10)

Some participants reported that even if the maternity services were aware of their mental health problems they did not address or discuss it with the women and left it up to the women to initiate disclosure and inform them that their mental health had deteriorated.

'Well they more or less said "well, you are attending a psychiatrist so they are looking after that.' (16)

'I found though the maternity services didn't really tend to take into account the bi-polar, so they weren't as supportive as they could have...they didn't make extra appointments, they didn't keep a watchful eye on me or anything like that....' (18)

For some women attending appointments was challenging sometimes because of previous negative experience in the maternity services or because of the impact of the mental health problem on self-esteem, which left them anxious and vulnerable. This was exacerbated by the apparent lack of any structured appointment system or the presence of a friendly face to help women navigate the system.

'...I had a fear going into the hospital [for appointments].... had all this work done [talking about previous traumatic birth] so I thought it was going to be the same again.' (11)

'Going public you're waiting a long time, you could be two hours waiting before you're seen'. (12)

'...It's just dog eat dog in there, there's no system, there's nobody telling you where you should be...people could be left sitting for hours and hours and then realise that they didn't report to the right nurses or knock on the right door.' (1) 
When some women came to the maternity services to give birth, they reported that the services were not well prepared to support their individual needs and in some cases did not explore their preferences and choices with them.

'They didn't really ask about the birth plan or...did I have any plans of how l'd like the birth to go myself, and I did but I didn't want to speak up like....I felt like that they thought they knew best.' (3)

'I had it (birth plan), but nobody ever asked me for one'. (12)

Unfortunately, the only way the service could facilitate one woman, who experienced childhood sexual abuse and had requested not to have any males present during labour and childbirth, was to plan for an induced labour. For another woman who had post-traumatic stress disorder and needle phobia following a previous birth, her carefully developed and agreed birth plan involving a caesarean section was, on the day of the birth, ignored by the anesthetist who tried to convince the women to have an epidural rather than general anaesthetic, thus causing her unnecessary distress and fear.

\section{Feeling misunderstood}

A major contributory factor to the lack of support women received was perceived to be due to the lack of time and a lack of knowledge and/or understanding amongst midwives of mental health difficulties in pregnancy and motherhood. Many of the women commented on the busyness of the midwives and the lack of time for them to engage in conversation or discussion.

'...just the midwives don't have the time in the postnatal wards, I don't think, to really talk to people and see how they are getting on. I think they look after the physical side of things...I don't feel that the staff were given the time.' (16)

Other women recounted numerous occasions when they had outwardly expressed signs of distress, which were ignored, misunderstood or responded to in a negative or inadequate 
manner. This occurred most often for women in the postnatal period when they struggled to connect with, and adequately care for, their baby whilst trying to make sense of their mental distress. Consequently, early signs of distress were missed:

"I just wouldn't hold the baby at all. I had the curtains closed...the nurses kept pulling the curtains around and saying "Come on, up, have your breakfast." and I was like, I didn't want to eat...Not one of them mentioned postnatal depression...I didn't know what was happening...one night I was really distressed and...they were getting quite cross with me..."Pull yourself together, this is ridiculous, like we can't sit and feed your baby all night, you have to do it".' (14)

'After the [caesarean section]...it was like the postnatal depression just hit me as soon as they took [baby's name] out and that whole time in the hospital I got no support...One of the nurses came in to me when I was crying, and turned and walked out and I was sitting at the edge of the bed, like, crying for a couple of hours...I understand that people can be busy, but it only takes two seconds to say "are you okay, can I do anything for you".' (13)

'...she[midwife] sort of came in, she was very cross with me...very firm, I suppose she, maybe that was just her job, I remember thinking, you know, it just wasn't the right approach for me...I don't like when anybody raises their voice or gives out, you know, l'd be quite a sensitive person.' (12)

However, there were some women who felt that their mental distress attracted the wrong type of support from health care professionals, especially those with a previous diagnosis of 'mental illness.' Instead of garnering positive support, which they so strongly desired, a number of the women recounted what they perceived as surveillance and monitoring of their mental distress, behaviour, and interaction with their baby. They believed that midwives were sceptical of their ability to care for their baby adequately whilst experiencing mental distress. 
'I was very emotional in the hospital, I was kind of always on guard and once they heard then that I was on [name of medication] ... I found I was being watched, do you know what I mean, "is she alright with that baby or isn't she".' (11)

Midwives were aware of the possibility of postnatal depression and in some cases did use the Edinburgh Postnatal Depression Scale (EPDS) as an assessment tool prior to a woman's discharge; however, in many instances the EPDS was administered as a 'check-list' rather than being used as part of an in-depth discussion with women about mental health.

\section{A veil of secrecy}

Women's mental health difficulties were further compounded by the apparent veil of secrecy surrounding perinatal mental health difficulties within maternity service provision. Many of the women felt a desire to know and understand more about mental health difficulties and what to do should they experience them. However, this information was entirely absent from the antenatal education women received in maternity services. Women perceived that the focus of antenatal education was on birth and breastfeeding with little recognition of the emotional impact of birth on women's mental health. If and when mental health issues were discussed it was primarily with reference to the "baby blues', with little or no acknowledgment of more severe mental health difficulties that could occur over the perinatal and early motherhood period, such as depression during pregnancy, postnatal depression, anxiety, or psychosis.

'No there wasn't [any information on mental health]. There was a big focus on a natural birth followed by "you have to breast feed or that'll be the end of the world".' (4)

'Not one of them mentioned postnatal depression, not one mentioned it, not one at all...it was really about the exercises and the breathing...the puff and blow classes I call them.' (14) 
'My spirits were extremely low in the early stages of pregnancy and I didn't know what was wrong with me then because nobody ever said that to me.' (12)

A number of women articulated that this dismissal of, and lack of engagement with, mental health difficulties was not solely due to lack of knowledge on midwives' part but was also symptomatic of a broader conspiracy of silence around mental health difficulties and childbirth that permeated both society in general and maternity care specifically. Thus, a number of the women believed that for midwives and other mothers to acknowledge and engage with mental distress would be tantamount to debunking the powerfully illustrious perception of motherhood as 'rosy', an overwhelmingly positive and rewarding experience, devoid of sadness or anxiety.

'If they said that in the antenatal class, or if someone came into you in the maternity after you had your baby and said things mightn't be rosy...but...we don't say it to each other so why do we expect nurses to come and say it then. Nobody wants to burst anyone's bubble, when they're having their first baby'. (4)

Inevitably, this veil of silence permeating the maternity services served to isolate women further and perpetuate the already evident stigma attached to mental distress in the perinatal period.

\section{A way forward: experiences of specialist Perinatal Mental Health Services}

Some of the women's perinatal experiences were good, in stark contrast to those previously discussed. The primary reason for this was that a specialist perinatal mental health service was available in the maternity unit they attended. These specialist services provided support specifically for women with mental health difficulties during the perinatal period and involved having direct access to a support midwife with expertise in mental health, or a mental health nurse and perinatal psychiatrist, in addition to telephone support when appointments were not practical and specific problems needed to be dealt with quickly. In contrast to the experiences of other women who found their mental health concerns were dismissed or underestimated, women in this cohort reported very little difficulty in 
accessing support, as the service appeared to be proactive in referring women and was very responsive in terms of appointments.

'Yeah, the midwife, she was just asking how was I, did I suffer from anything? And I told them straight away and bang, straight away they rang up [name counsellor/ midwife who specialised in mental health] said she would see me, "just tell her to ring, and you'll get an appointment within two days".' (8)

'I was asked if I'd like to talk to someone so I said "Yes". So [name] is the midwife [support midwife]...fantastic, from the time I went to see her things got a lot easier...I went to see her before the structural scan at 20 weeks and she was great, she helped me cope with what I was feeling and you know saying things that you are afraid to say.' (5)

'I was roaring crying. I was in an awful state, thinking, I felt so bad and yet I was afraid to take medication in case it hurt the baby. And she [GP] reassured me that it wouldn't, that I needed it, and she rang the [hospital] as I sat there and asked for the support services and the [name of specialist maternity service] rang me the next day with an appointment...[Name of support midwife] she visited me in hospital every day I was in there, for a chat. She was very good, yeah.' (6)

The emotional and informational support women received whilst attending the specialist service was reported to be excellent and extremely beneficial as, unlike their counterparts, they were afforded dedicated time and information, and had someone that they could rely on for support throughout the pregnancy. They also reported that they were afforded multiple opportunities to discuss their worries or concerns openly in a non-judgemental and comforting environment.

'...it was a saving grace, because I don't know what state of mind I'd be in now if I hadn't [her]...And I'm absolutely terrified I'm going to go through the whole lot again now after the birth, so, but they won't let that happen they said...And I just feel like I 
have a backbone there backing me up and I know if I'm ever really, really bad I can always have someone to turn to, which is the most important thing.' (8)

These practitioners also acted as advocates for women to ensure their needs were addressed when they entered the maternity service. The isolation that other women attending generic mainstream services encountered was not evident, neither was the veil of secrecy or feeling of surveillance present as women felt supported for the duration of the perinatal period and sought comfort from the consistency, continuity, and dependability of care that the service provided.

'The morning I was going down for the caesarean, she [name midwife/counsellor] came into me. She came up after the birth, like you know, and she sat with me and I was breast-feeding and she helped me get that going...and she went through postnatal depression and gave me leaflets and the signs to look out for and to contact her if I had any problems or anxieties or anything. I was very lucky. The service I got was fantastic'. (5)

For some women, especially those of who were anxious, or receiving conflicting advice, about medication, having access to specialist advice was important.

'Well, as soon as I found out I was pregnant I came off medication I was taking for panic attacks and I had my first kind of check-up in the [maternity unit] at 17 weeks ... by that stage I was suffering quite bad with the anxiety that I wasn't able to get out of the house and I was quite sick as well during the pregnancy which kind of made me even more nervous and more anxious .... So I mentioned it to the midwife ...they put me in touch with [name mental health nurse] in the [maternity unit] who was absolutely wonderful, the following day, she [mental health nurse] rang... to say [perinatal psychiatrist] had a cancellation and could I come in that afternoon and ... I found out that the medication I was on was perfectly safe...because I was well into 17 weeks at that stage that there was no concern. And it was one of the medications that you'd be allowed breastfeed on as well, so it wouldn't get into the baby's 
system. It was just so reassuring to hear that and find that something could be done and yeah from that date on things got so much better'. (9)

\section{DISCUSSION}

For women who experience perinatal mental health problems, rapid access to appropriate specialist services and treatment is recommended to lessen women's distress and the possible negative impact on the baby (Royal College of Psychiatrists 2002, NICE, 2014). The findings of this study highlight an evident lack of specialist services and inter-disciplinary referral between maternity and mental health services which resulted in many of the women in this study receiving fragmented care and 'falling through the cracks'. Consequently, the vast majority of the women felt unsupported within the maternity care services and were of the view that physicality and biomedical aspects of pregnancy appeared to be prioritised to the detriment of their mental and emotional state. While this may be part due to the absence of specialist services, this philosophy of care may also be indicative of the growing medicalisation of the perinatal period (Johanson et al., 2002, Parry, 2006, Benoit et al., 2010, Christiaens et al., 2013) and the ensuing perception of woman as physical vessels for the foetus, devoid of emotional and cognitive needs (Annas, 1986, Wetterberg, 2004, Ogle et al., 2011, Meurk et al., 2014)

Some research suggests that women may be reluctant to disclose mental health problems for fear of stigma and loss of custody (Boots Family Trust, 2013), but this was not the case for all of the women in this study, with some, like the women in Darwin et al's (2015) study, volunteering their mental health history to the midwife during their booking encounters. Even when the women voluntarily disclosed, the midwives appeared to lack the knowledge and skills to respond sensitively and responsively, and tended to revert responsibility onto the woman to seek help if required. It could also be said that this lack of responsiveness to the women's disclosure, coupled with the lack of discussion on mental distress during antenatal education, not only left the women without vital information but served to instil in the mothers a sense of rejection and stigma surrounding their mental health difficulties. In addition, this lack of receptiveness, recognition and action has the potential to impact negatively on women's future disclosure, by perpetuating the belief that maternity care practitioners or services are not interested in their mental wellbeing. 
Although it cannot be certain that midwives consciously conveyed and created an atmosphere of surveillance and scepticism in their interactions with women, the feeling of being observed and watched as they cared for their baby was reported by some women and reflects previous research findings in this area (Hendrick and Daly, 2000, Montgomery et al., 2006, Davies and Allen 2007). The interactions between women and midwives may have been informed by an iterative process occurring between the possible mediating factor of women's self-stigmatisation, and their negative self-perception of their ability to care for their babies to the best of their ability, and midwives' surveillance behaviour. The surveillance described may also be influenced by the focus on child protection legislation in the Republic of Ireland, which places a significant responsibility on all health professionals to identify children at risk (Department of Health and Children, 2004). Whilst the need for health professionals to assess women's ability to parent is understandable and necessary, such an assessment should be performed professionally, transparently, and fairly with due cognisance of the vulnerabilities and challenges faced by mothers experiencing mental health problems.

Midwives lack of knowledge, understanding and attention to the emotional aspect of women's lives also resulted in explicit indicators of women's mental distress, like disrupted sleep patterns and emotional upset, being dismissed or ignored. While this finding is in line with previous research which indicate that midwives lack knowledge and confidence in discussing mental health issues and referring women to appropriate resources (Buist et al., 2006, Mivsek et al., 2008, Işik and Bilgili, 2010, Jones et al., 2010, McCauley et al., 2011), midwives were also cited as being ideally placed to engage with, and provide therapeutic support to, women with mental distress (Gamble et al., 2004, Hanna et al,. 2004, Jones et al., 2010). As $90 \%$ of midwives in Ross-Davie et al's (2006) study were of the view that psychological care is a core part of their role, the issue appears to be more about knowledge than willingness; hence, there is a need to include a module on motherhood and perinatal mental health issues, in all undergraduate and postgraduate midwifery programmes. While studies do demonstrate the positive outcomes of education in the area of postnatal depression and screening tools (Gerrard et al., 1993, Ross-Davie et al., 2006, Jardri et al., 2010). As women may experience the re-emergence of past mental health issues, in 
addition to development of problems for the first time there is a need to broaden education beyond postnatal depression. Any module developed needs to address issues such as psychosis, anxiety, eating disorders, bipolar disorders, depression during pregnancy, suicide and the use of psychotropic medication (Higgins et al., 2016). In addition, the module should aim to address skills to assess, support and provide appropriate referrals for women. Midwives need to be aware that undiagnosed problems can have seriously negative consequences for women, including relapse of existing mental health problem and in the extreme case, maternal suicide (CMACE, 2011). Mental health problems during pregnancy are also associated with an increased risk of pre-term delivery and growth retardation (Ding et al 2014., Kim et al., 2013).

Women's experiences in this study of accessing and receiving support for their mental health problems were much improved when a specialist perinatal mental health midwife or nurse was available to them, supporting the findings of Phillips and Thomas (2015). The care given by these services ensured that women felt understood, and supported an atmosphere of safety and acceptance, which in turn promoted and encouraged women's disclosure of their mental health concerns and needs. Such specialist services are welcomed and definitively demonstrate a 'best practice' model of care in line with guidelines (NICE, 2014, SIGN, 2012).

\section{Conclusion}

A key finding of the study is the contrasting experiences of women who attended maternity services with and without specialist mental health services provided. Even when the midwifery team were aware of the women's mental health history they appeared to lack the knowledge, skill and competence to engage in an empathetic, compassionate and caring manner. In contrast, women who attended maternity units with access to specialist mental health services were identified as needing support early in pregnancy, referred promptly, and received appropriate education, support and treatment throughout their pregnancy.

Despite the fact that generalisability of findings is reduced, as the study was conducted with a small number of women, with a lack of representation of ethnic minority women, and 
limited by the fact that only two services in the Republic of Ireland at the time of the study had specialist perinatal mental health services, the study offers valuable insights into the views of women with mental health problems of their maternity care experience, and highlights the deficits and fragmentation of care within services that do not have a specialist mental health service. In addition, the findings support the need to further develop perinatal mental health services within the Republic of Ireland, so that quality service provision is not dependent on geography. While opportunities for expansion of such services are often resource-finite, future improvements must also target the demonstrable lack of knowledge and understanding of maternal mental distress amongst most maternity care practitioners.

\section{Table 1: Topic guide for interview}

\section{Personal history}

- History of mental health problems, duration, nature etc

- Contact/support offered by mental health services

- Current treatment (Medication if any)

Interactions with and attitudes of staff (throughout the continuum)

- Disclosure (Barriers and facilitators)

- Knowledge of staff of mental health issues

- Attitudes and responsiveness of staff to specific mental health needs

\section{Mental health support and services}

- Availability of appropriate information on mental health issues (Pre and postnatal)

- Links between midwifery services and mental health care services

- Availability of perinatal mental health services within maternity services

- Barriers to, or facilitators of access to mental health support and services

- How access to mental health service services was facilitated

\section{Experience of birth and immediate postnatal period}

- Opportunity to exercise choice in childbirth and manage personal identity

- Levels of support and responsiveness of staff to mental health needs

- Discharge planning \& community follow up.

\section{REFERENCES}

Annas G. J., 1986. Pregnant women as fetal containers. Hastings Center Report 16, 13-14. 
Benoit, C., Zadoroznyj, M., Hallgrimsdottir H., Treloar A. and Taylor K., 2010. Medical dominance and neoliberalisation in maternal care provision: The evidence from Canada and Australia. Social Science \& Medicine 71, 475-481.

Boots Family Trust Alliance, 2013. Perinatal Mental Health: Experiences of Women and Health Professionals. www.tommys.org/file/Perinatal Mental Health 2013.pdf. [Accessed $13 / 07 / 2015]$.

Buist, A., Bilszta, J., Milgrom, J., Barnett, B., Hayes, B. and Austin, M.P., 2006. Health professional's knowledge and awareness of perinatal depression: Results of a national survey. Women and Birth 19, 11-16.

Centre for Maternal and Child Enquires (CMACE).,2011. Saving Mothers Lives: Reviewing maternal deaths to make motherhood safer: 2006-2008. The Eighth Report of the Confidential Inquires into Maternal Deaths in the United Kingdom British Journal of Obstetrics and Gynaecology, 118 (Suppl 1), 1-203 http://www.centreformidwiferyeducation.ie/wpcontent/uploads/2011/03/CMACE2011-Saving-Mothers-Lives-Reviewing-maternal-deaths-to-make-motherhood-safer2006-2008.pdf Accessed 15th February 2015

Christiaens, W., Nieuwenhuijze, M. J. and De Vries, R., 2013. Trends in the medicalisation of childbirth in Flanders and the Netherlands. Midwifery 29, e1-e8.

Davies, B. and Allen, D., 2007. Integrating 'mental illness' and 'motherhood': The positive use of surveillance by health professionals. A qualitative study. International Journal of Nursing Studies 44, 365-376.

Darwin, Z., McGowan, L., and Edozien, L., 2015. Antenatal mental health referrals: Review of local clinical practice and pregnant women's experiences in England. Midwifery 31, e17e22.

Department of Health and Children, 2004. Children first: National guidelines for the 
protection and welfare of children. The Stationery Office, Dublin.

Ding, X.-X., Wu, Y-L., Xu, S-J., Zhu, R-P., Jia, X-M., Zhang, S-F., Huang, K., Zhu, P., Hao, J-H., and Tao, F-B., 2014. Maternal anxiety during pregnancy and adverse birth outcomes: A systematic review and meta-analysis of prospective cohort studies." Journal of Affective Disorders 159, 103-110.

Fendrich, M., Warner, V. and Weissman, M. M., 1990. Family risk factors, parental depression, and psychopathology in offspring. Developmental Psychology 26, 40-50.

Gamble J., Creedy, D., and Moyle, W.,2004. Counselling processes to address psychological distress following childbirth: Perceptions of midwives. Australian Midwifery Journal of the Australian College of Midwives 17, 16-19.

Gerrard, J., Holden, J., Elliott, S., McKenzie, P., McKenzie, J., and Cox, J.L., 1993. A trainer's perspective of an innovative programme teaching health visitors about the detection, treatment and prevention of post-natal depression. Journal of Advanced Nursing 18, 18251832.

Goodman, S. H. and Brumley, H. E., 1990. Schizophrenic and depressed mothers: Relational deficits in parenting. Developmental Psychology 26, 31-39.

Hammen, C., Burge, D. and Stansbury, K., 1990. Relationship of mother and child variables to child outcomes in a high-risk sample: A causal modeling analysis. Developmental Psychology, 26, 24-30.

Hanna, J. H., Savage, S., and Layton, K., 2004. The early detection of postpartum depression: Midwives and nurses trial a checklist. Journal of Obstetrics Gynaecology Neonatal Nursing 33, 191-197.

Hendrick, V. and Daly, K., 2000. Parental Mental Illness. In: Halfon, N., Shulman, E., Hochstein, M. and Shannon, M. (Eds.), Building Community Systems for Young Children, 
UCLA Center for Healthier Children, Families and Communities, 2000.

http://eric.ed.gov/?id=ED470406. [Accessed 04/01/2016].

Higgins, A., Carroll, M., and Sharek, D., 2012. 'It opened my mind': student midwives views of a motherhood and mental health module. MIDIRS Midwifery Digest 22, 287-292.

Higgins, A., Carroll M., and Sharek, D., 2016. Impact of perinatal mental health education on student midwives' knowledge, skills and attitudes: a pre/post evaluation of a module of study. Nurse Education Today 36, 364-369

Işik S.N., and Bilgili N., 2010. Postnatal depression: Midwives and nurses' knowledges and practices. Erciyes Medical Journal 32, 265-274.

Jardri, R., Maron, M., Pelta, J., Thomas, P., Codaccioni, X., Goudemand, M., and Delion P., 2010. Impact of midwives' training on postnatal depression on screening in the first week post delivery: a quality improvement report. Midwifery 26, 622-629.

Johanson R., Newburn M. and Macfarlane A., 2002. Has the medicalisation of childbirth gone too far? British Medical Journal 324, 892-895.

Jones C.J., Creedy D.K. and Gamble J.A., 2010. Australian midwives' attitudes towards care for women with emotional distress. Midwifery 28, 216-221

Kelly, R. H., Danielsen, B. H., Golding, J. M., Anders, T. F., Gilbert, W. M. and Zatzick, D. F., 1999. Adequacy of prenatal care among women with psychiatric diagnoses giving birth in 1994 and 1995. Psychiatric Services 50, 1584-1590.

Kim, D. R., Sockol, L. E., Sammel, M. D., Kelly, C., Moseley, M., and Epperson, C. N., 2013. Elevated risk of adverse obstetric outcomes in pregnant women with depression. Archives of Women's Mental Health 16, 475-482. 
McCauley, K., Elsom, S., Muir-Cochrane, E., and Lyneham, J., 2011. Midwives and assessment of perinatal mental health. Journal of Psychiatric and Mental Health Nursing 18, 786-795.

Mivsek, A.P., Hindley, V., and Kiger, A., 2008. Slovenian midwives' and nurses' views on post-natal depression: an exploratory study. International Nursing Review 55, 320-326.

Montgomery, P., Tompkins, C., Forchuk, C. and French, H., 2006. Keeping Close: Mothering with Serious Mental Illness. Journal of Advanced Nursing 54, 20-28.

Meurk, C., Broom, A. and Adams J., 2014. Relative bodies of knowledge: Therapeutic dualism and maternal-foetal individuation. Social Theory and Health, 12, 159-178.

Munk-Olsen, T., Laursen. T.M., Pedersen, C.B., Mors, O., Mortensen. P.B., 2006. New parents and mental disorders: population-based register study. Journal of the American Medical Association 296, 2582-2589.

Munk-Olsen, T., Laursen, T.M., Mendelson, T., Pedersen, C.B., Mors, O., Mortensen, P.B., 2009. Risks and predictors of readmission for a mental disorder during the postpartum period. Archive of General Psychiatry 66, 189-195.

Mullick, M., Miller, L. J. and Jacobsen, T., 2001. Insight Into Mental Illness and Child Maltreatment Risk Among Mothers With Major Psychiatric Disorders. Psychiatric Services $52,488-492$.

National Institute for Health and Clinical Excellence (NICE)., 2014. Antenatal and postnatal mental health: clinical management and service guidance. National Collaborating Centre for Mental Health (UK). http://www.nice.org.uk/guidance/cg192. [Accessed $31 / 12 / 2015]$.

Oates, M., and Cantwell, R., 2011. Deaths from psychiatric causes. In: Centre for Maternal 
and Child Enquiries (CMACE), Saving Mothers' Lives: Reviewing Maternal Deaths to Make Motherhood Safer: 2006-2008. The Eighth Report of the Confidential Enquiries into Maternal Deaths in the United Kingdom. British Journal of Obstetrics and Gynaecology 118, 1-203.

Ogle, J. P., Tyner, K. E. and Schofield-Tomschin S., 2011. Watching over baby: Expectant parenthood and the duty to be well. Sociological Inquiry 81, 285-309.

Parry, D. C., 2006. Women's lived experiences with pregnancy and midwifery in a medicalized and fetocentric context six short stories. Qualitative Inquiry, 12, 459-471.

Phillips, L., and Thomas,.D., 2015. The first antenatal appointment: an exploratory study of the experiences of women with a diagnosis of mental illness. Midwifery 31, 756-764.

Ross, L., and McLean, L., 2006. Anxiety disorders during pregnancy and the postpartum period: a systematic review. Journal of Clinical Psychiatry 67, 1285-1298.

Ross-Davie, M., Elliott, S., Sarkar, A., and Green, L., 2006. A public health role in perinatal mental health: Are midwives ready? British Journal of Midwifery 14, 330-334.

Royal College of Psychiatrists., 2002. Patients as parents addressing the needs including the safety of children whose parents have mental illness. Royal College of Psychiatrists, Council Report CR105.

Scottish Intercollegiate Guidelines Network (SIGN)., 2012. Management of perinatal mood disorders: A national clinical guideline. www.sign.ac.uk. [Accessed 11/05/2015].

Viguera, A.C., Whitfield, T., Baldessarini, R.J., Newport, D.J., Stowe, Z., Reminick, A., 2007. Risk of recurrence in women with bipolar disorder during pregnancy: prospective study of mood stabilizer discontinuation. American Journal of Psychiatry 164, 1817-1824. 
Watson, H.J., Von Holle, A., Hamer, R.M., Knoph Berg, C., Torgersen, L., Magnus, P., Stoltenberg, C., Sullivan, P., Reichborn-Kjennerud, T., and Bulik, C.M., 2013. Remission, continuation and incidence of eating disorders during early pregnancy: a validation study in a population-based birth cohort. Psychological Medicine 43, 1723-1734

Wetterberg A., 2004. My body, my choice... my responsibility: The pregnant woman as caretaker of the fetal person. Berkeley Journal of Sociology 48, 26-49. 